\title{
La tradició literària en la poesia de Pere Rovira: el cas de Trio en do menor
}

\section{The literary tradition of Pere Rovira's poetry: The case of Trio en do menor}

\author{
Joan Calsina Forrellad \\ Universitat Autònoma de Barcelona \\ joancalsina@gmail.com
}

Data de recepció: $28 / 03 / 2018$

Data d'aceptació: 14/06/2018

\section{Resum}

En aquesta comunicació estudiarem l'ús de la tradició literària en l'obra recent de Pere Rovira. Tanmateix, per abordar aquesta qüestió, ho farem a través d'un exemple il·lustratiu del seu ús del llegat literari; en concret, basarem les nostres explicacions en l'anàlisi del poema Trio en do menor, pertanyent al darrer recull publicat fins ara per part de Rovira, que duu per títol Contra la mort. Posarem aquest text en relació amb algunes de les composicions que poden haver servit de model a l'hora de compondre'l, o que, en tot cas, han exercit una certa influència sobre el poema resultant; ens referim a Escuchando la música sacra de Vivaldi, de Vicente Gallego, En el silenci obscur d'unes parpelles closes, de Màrius Torres, i La Musique, de Charles Baudelaire. Així, a través d'aquest exemple específic, esperem demostrar la transformació estètica de l'autor català, que ha basculat des d'una certa confluència amb la poesia de l'experiència dels anys vuitanta fins a desenvolupar un caràcter més propi i personal, determinat en gran manera per allò que hem resolt a anomenar la «tendència classicitzant» de l'autor.

Paraules clau: Pere Rovira; Charles Baudelaire; poesia contemporània; tradició literària; música.

\begin{abstract}
In this notice we will study the literary tradition used in Pere Rovira's recent poetry. However, in order to understand this subject, we shall do it with an illustrative example of his literary legacy use. In fact, we shall support our explanations in the poem called Trio en do menor, included in the last Pere Rovira's poetry book called Contra la mort-«Against death». We shall relate the original text with other poems that can have been a model in his work, or that they have probably contributed to that: we are talking about Escuchando la música sacra de Vivaldi, by Vicente Gallego, En el silenci obscur d'unes parpelles closes, by Màrius Torres, and La Musique, by Charles Baudelaire. In that way, through this specific example, we will be able to demonstrate Pere Rovira's esthetical transformation swinging between some confluence of the poetry of experience in the 80 s until the development of a more personal character, determinated, in some way, by the attitude which we call the «classical tend» of the author.
\end{abstract}

Key words: Pere Rovira; Charles Baudelaire; contemporary poetry; literary tradition; music. 

Taula de continguts

1. Introducció

2. El cas de Trio en do menor

Bibliografia 



\section{Introducció}

Pere Rovira ha esdevingut, ja des de fa temps, però sobretot en la darrera dècada, una de les veus més singulars, valuoses i transcendents del panorama literari català. Per molts especialistes i companys de professió és indiscutible que cal considerar Rovira com una de les figures més rellevants del panorama poètic actual en llengua catalana. Sens dubte, es tracta d'un escriptor amb una obra àmplia, sòlida, de contrastada qualitat: a banda d'haver publicat cinc llibres de poesia -alguns d'ells distingits amb els guardons més prestigiosos en el seu àmbit-, també ha escrit un gran nombre d'obres en gèneres ben diversos: dues novel·les, tres volums de traducció, dos dietaris, diverses antologies, a més de cinc obres assagístiques i multitud d'articles acadèmics. Pere Rovira és, també, doctor en filologia, un dels experts més reconeguts en l'obra de Jaime Gil de Biedma, i professor emèrit de la Universitat de Lleida. I és justament des d'aquesta ciutat, Lleida, des d'on ha exercit una notable influència en escriptors de prestigi com Txema Martínez, Pere Pena, Emili Bayo, Enric Sòria, o Víctor Obiols, per citar-ne només uns pocs exemples. I, a més de tot això, no podem deixar de fer esment a la importància que ha tingut Rovira en les relacions entre la poesia catalana i espanyola dels darrers trenta anys; no en va, el poeta català ha mantingut durant dècades una intensa relació personal i artística amb autors tan significatius de les lletres espanyoles com Luis García Montero, Vicente Gallego, Carlos Marzal, Javier Egea, Álvaro Salvador, Antonio Jiménez Millán o Francisco Díaz de Castro.

Pel que fa al conjunt de la seva obra poètica, es tracta d'un corpus relativament breu, format per un total de cinc reculls escrits entre els anys 1981 i 2011: Distàncies (1981), Cartes marcades (1989), La vida en plural (1996), La mar de dins (2003) i Contra la mort (2011). De manera sintètica, podem afirmar la seva poesia es caracteritza per una marcada tendència al realisme, i que, així mateix, les vivències pròpies i personals del poeta tenen un pes molt considerable en l'aspecte temàtic de les composicions. El subjecte poètic predominant en el conjunt de la seva obra sol ser algú proper a la seva experiència, a la seva personalitat $i$ al seu caràcter, $\mathrm{o}$, en tot cas, coherent amb la seva personalitat i el seu caràcter. Les seves creacions acostumen a vincular-se a les vivències individuals i a la quotidianitat, a allò que ell mateix ha definit en altres contextos com a «vida viscuda» (Rovira, 2009: 19). Al mateix temps, però, els 
seus textos sempre inclouen un grau d'abstracció més o menys important, això és, de reflexió i de voluntat de transcendència. Rovira busca en tot moment oferir elements que ultrapassin el mer registre d'anècdotes trivials, i plantejar, en canvi, un tractament reflexiu davant les observacions i actituds que les situacions quotidianes puguin plantejar. D'aquí que tot sovint s'hagi emmarcat el conjunt de la seva obra dins l'escola de poetes de l'experiència o dins el corrent del realisme moral, o que, fins i tot, en ocasions, se l'hagi qualificat de «moralista cordial» (Margarit, 2003: 26).

Des del punt de vista de les influències literàries, al llarg de la seva trajectòria poètica podem distingir dues grans etapes. La primera, composta pels dos primers 1libres, Distàncies i Cartes marcades, és on l'empremta dels autors del realisme crític-especialment Jaime Gil de Biedma i Gabriel Ferrater- resulta predominant. A partir del tercer 1libre, La vida en plural, la proximitat amb aquesta escola poètica va perdent intensitat. Però és, sobretot, en les dues darreres obres, La mar de dins i Contra la mort, on se n'allunya de forma definitiva. A partir d'aquests dos reculls, Pere Rovira inicia una etapa del tot distinta, que hem resolt a anomenar la tendència classicitzant de l'autor, atès que els seu interessos $\mathrm{i}$ influències van cada vegada més enrere en el temps. En els dos darrers llibres -però sobretot a Contra la mort-podem percebre de manera indubtable un major interès per la poesia clàssica, entenent aquest concepte en un sentit ampli i no restrictiu. Rovira tendirà sovint a cercar cada cop més enrere en la tradició, a allunyar-se sovint de la contemporaneïtat i buscar referències ja no només en el segle XX sinó també en èpoques anteriors. Es tracta d'una tendència que, de fet, ja s'intuïa en llibres precedents i que ara, de forma gradual, s'anirà fent més i més marcada. En aquest sentit, la tradició francòfona resultarà notablement rellevant, en especial aquell corrent estètic que, de Valéry fins als nostres dies, s'ha conegut amb la denominació - potser no del tot afortunada-de simbolisme. Un corrent on Baudelaire, és clar, hi tindrà un paper preeminent -de fet, es convertirà en un autor cabdal per a Rovira-, però també Paul Verlaine esdevindrà tot sovint una referència. Així mateix, la continuïtat catalana d'aquesta escola resultarà de gran interès per al poeta, que aprofundirà en l'obra d'autors com Màrius Torres o Joan Sales. 


\title{
2. El cas de Trio en do menor
}

Establerts aquests principis introductoris, entrem ja en l'objecte de la nostra anàlisi, a saber, el comentari específic del poema Trio en do menor. Es tracta d'una composició que forma part del darrer recull de Pere Rovira, Contra la mort, publicat l'any 2011 (Rovira, 2011: 57). Primerament, cal fer notar que el poema presenta una estricta construcció formal. Trio en do menor és un sonet compost per versos decasíl·labs amb rima consonant. Un tipus d'estructura tancada, complexa, que malauradament no és gaire habitual entre els autors coetanis, i que també demostra, ja de bon principi, la marcada tendència classicitzant de Rovira a la qual ens hem referit una mica més amunt.

En aquest sonet, l'autor presenta les reflexions d'un subjecte poètic que, davant de l'audició d'una peça musical -en concret, el trio en do menor de Haydn-se sent colpit de forma poderosa, íntima i profunda. La música el commou en gran manera i el porta a desenvolupar unes sensacions intenses, el condueix a assolir, gairebé, un veritable estat d'epifania, de revelació, de catarsi. És en aquest context que el protagonista de la composició decideix adreçar-se directament la música, interpel·lar-la, ben bé com si fos una persona de carn i ossos amb qui es pogués dialogar, i li pregunta sobre el sentit veritable de les emocions que experimenta. Vegem tot seguit el poema:

\section{TRIO EN DO MENOR}

HAYDN

\author{
Santa música, ¿on caus?, ¿en quina vena \\ de mi véns a buscar-me? El plor de fel \\ d'un cor apedregat, violoncel, \\ ¿raja de tu, o el sent la meva pena? \\ El xiscle d'enyorança, violí, \\ que tendrament sota el teu arc tremola \\ és com una navalla que s'esmola \\ en moles de dolor dintre de mi. \\ Cordes que lligueu l'art i la tristesa, \\ $¿$ ¿no podria una almoina musical \\ trencar-vos l'harmonia funeral? \\ És un cant generós de la bellesa
}


i em fa la caritat que li demano

l'alta rialla d'aigua del piano.

D'entrada, cal destacar el to que presenta el conjunt del poema. Es tracta d'un to sens dubte transcendent, punyent, d'una intensitat notable, i gairebé podríem dir, fins i tot, arriscat: la profunda agitació interior, la gran emotivitat, situa el text quasi al límit d'una efusió sentimental excessiva. Tanmateix, l'expressió d'aquestes emocions se sustenta, precisament, gràcies a la sòlida exigència tècnica i formal del poema, a l'excel·lent factura lingüística i també a la qualitat de les seves imatges.

D'altra banda, és pertinent remarcar la presència en aquest text d'allò que, a falta d'un terme més adequat, podríem qualificar d'una certa inclinació de tipus místic o espiritual. En efecte, sembla com si la veu poètica atorgués a la música una capacitat inaudita, com si l'autor vinculés els sons harmònics i la rítmica pulsació amb alguna cosa que va més enllà de l'experiència mundana, més enllà de la pròpia percepció ordinària de les coses. En aquest sentit, hem de ressaltar l'ús del terme «santa música»-són les primeres paraules del poema-, que implica a tots els efectes unes clares connotacions religioses. L'ús de l'adjectiu santa no sembla pas una mera casualitat en el context general de la composició. Per tant, podem aventurar-nos a afirmar que Trio en do menor atorga a la música un relleu inusitat, algun tipus d'essència quasi sobrenatural, d'una certa religiositat, la qual, endemés, ajuda a canalitzar les emocions del subjecte poètic. Una forma de misticisme que, fins a Contra la mort, era molt poc habitual al llarg de la producció de Pere Rovira.

Ara bé, cal remarcar, d'altra banda, la naturalesa ambigua que presenten les emocions a què acabem de fer referència. I és que no es tracta, en cap cas, d'una emotivitat monolítica ni uniforme sinó més aviat complexa, matisada, una emotivitat que bascula entre el dolor intens i una joia lleugerament alegre i esperançada. Fixem-nos, per exemple, en el segon quartet del poema: el jo poètic afirma que el «xiscle» del violí, és ben bé com «una navalla que s'esmola en moles de dolor», unes moles que, metafòricament, giren dins del seu propi cos; una imatge ben dura, fosca i anguniosa. En canvi, en els darrers passatges del poema, aquest dolor produït per la música sembla haver-se diluït per esdevenir, en canvi, «un cant generós de la bellesa» que li fa 
la caritat que li demana «l'alta rialla d'aigua del piano»; unes expressions que semblen mostrar, d'entrada, una perspectiva molt més positiva, més lluminosa. Per tant, sembla que es produeixi algun tipus de canvi o transformació en els sentiments exposats. Tenint en compte aquest fet, com hauríem d'interpretar les emocions del subjecte poètic? Quina seria la descripció exacte del seu estat emocional? I, així mateix, quina és la perspectiva concreta que vol defensar el text en relació amb la música i la seva naturalesa?

Per respondre aquestes preguntes, resulta especialment útil abordar la qüestió a través d'una anàlisi de tipus comparatiu. Tot seguit, presentarem una sèrie de textos que, si bé no podem afirmar de forma taxativa que siguin models directes de Trio en do menor, és probable que hagin exercit una influència prou important sobre aquest poema, o que, en tot cas, presenten algun tipus de concomitància amb la composició de Pere Rovira.

En primer lloc, no és sobrer esmentar que aquesta perspectiva mística de la música, gairebé sagrada, ha estat una idea abordada més o menys recentment per diversos dels autors que, durant els anys vuitanta, havien format part de l'anomenada poesia de l'experiència -un corrent líric amb què, no en va, Rovira va mantenir una estreta relació. La lloança de la música i el plaer, el gaudi sensitiu i la celebració de la vida, fins i tot un marcat optimisme vital, són elements que apareixen, per exemple, en els poemes de l'autor valencià Vicente Gallego, com és el cas d'aquesta composició titulada Escuchando la música sacra de Vivaldi (Gallego, 2002: 97):

\section{ESCUCHANDO LA MÚSICA SACRA DE VIVALDI}

A Carlos Marzal y Felipe Benítez Reyes

Como agua bendita,

como santo rocío tras la noche de fiebre

lava el alma esta música con su perdón sincero,

fluyente arquitectura que en el aire vertebra

la ilusión de otra vida

salvada ya para gozar la gloria

de un magnánimo dios.

De lo terrestre naces,

del metal y la cuerda, de la madera noble,

de la humana garganta

que estremecida afirma la hora suya en el mundo;

y sin embargo vuelas, gratitud hecha música, 


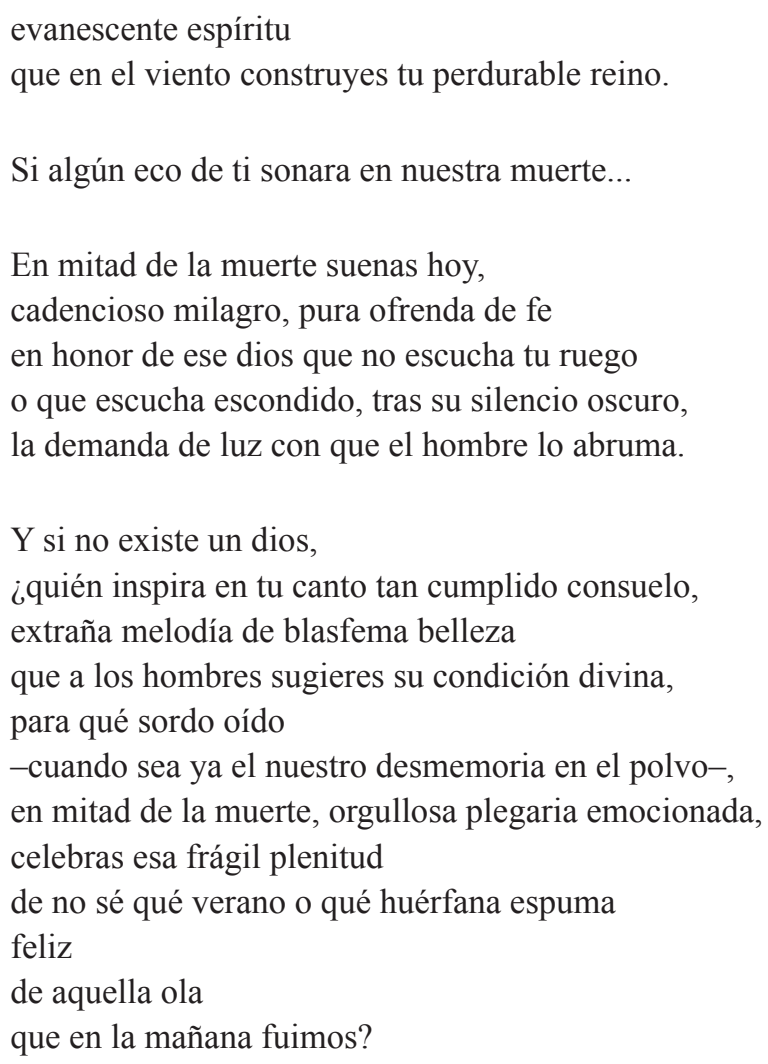

Sens dubte, els paral·lelismes d'aquesta composició amb la de Rovira són prou clars: el sentiment intens i elevat, el component místic o religiós, la personificació de la música i l'ús de les preguntes retòriques. És una actitud, aquesta admiració davant l'essència de la música, que aproxima les dues composicions. Seria lògic creure, doncs, que aquesta mena de posicionaments podrien estar vinculats, si més no en part, a l'evolució dels principis artístics dels poetes de l'experiència.

No obstant això, voldríem fixar l'atenció de forma més aprofundida en un segon autor i un segon text que, en principi, semblarien més allunyats de l'estil poètic més estrictament contemporani. Ens referim a un sonet de Màrius Torres: En el silenci obscur d'unes parpelles closes (Torres, 2010: 40). Es tracta d'una composició en què, com en el casos anteriors, l'audició d'una peça musical esdevé l'element que vehicula el text. La veu poètica ens descriu les emocions que desenvolupa a l'hora de percebre la música i insisteix en el poder espiritual, quasi diví, d'aquesta expressió artística: 
"EN EL SILENCI OBSCUR D’UNES PARPELLES CLOSES..."

La musique souvent me prend comme une mer!

Baudelaire

En el silenci obscur d'unes parpelles closes que tanca l'Univers en el meu esperit, la música s'enlaira. - Talment, en l'alta nit, puja fins als estels el perfum de les roses.-

Ella, divina música!, en el meu cor petit fa cabre l'infinit, trencades les rescloses, i se m'emporta lluny dels Nombres i les Coses, més enllà del desig, quasi fins a l'oblit.

Com les algues que avancen en el pit de les ones entre el bleix de les aigües rítmiques i pregones, jo vaig música endins, voluptuosament.

I mentre el món es perd, adormit a la platja, jo somnio - perdut en l'estreta salvatge dels llavis de l'escuma i dels braços del vent.

El poema de Torres, com el de Rovira, destaca per una bella factura formal, una extraordinària qualitat en les imatges i un cert preciosisme lingüístic. Pel que fa al paper de la música, en el cas de Màrius Torres aquesta es converteix, sobretot, en una benedicció, una defensa, una manera d'embriagar-se i evadir-se dels turments i les incerteses amb què la realitat, el món autèntic i palpable, aclapara el subjecte poètic. És una manera de superar, o si més no esquivar, els embats dolorosos de l'existència. A través d'una sèrie d'imatges poderoses, centrades, en especial, en l'ús d'elements marins -les algues, les ones, la platja, el vent, etc.-el poeta mostra la seva manera de comprendre el fenomen musical: no és sinó un mitjà, una ajuda, per apartar-se del dolors de la vida; el jo poètic només desitja restar adormit, somiant, envoltat només pels «llavis de l'escuma i els braços del vent».

Tanmateix, malgrat aquesta voluntat de protecció, el poema també presenta, com passava a Trio en do menor, l'expressió d'una emoció intensa, portada al límit, que no oculta el dolor i el patiment que s'amaguen darrera les afinades melodies. Un cert patetisme que, com dèiem abans, s'aconsegueix contenir i reïx a ser comunicable gràcies, sobretot, a l'altíssima qualitat del treball artístic. Endemés, també per Torres la música té un component religiós o místic; no és gratuït, sens dubte, l'ús del terme «divina música» -un concepte molt proper a l'emprat per 
Rovira, «santa música»-, cosa que li atorga al poema aquesta dimensió espiritual, religiosa i quasi sobrenatural. Tot plegat fa que els paral·lelismes entre el sonet de Rovira i el de Torres siguin prou evidents.

Però si anem encara una mica més enllà, és molt significatiu observar l'epígraf que apareix a En el silenci obscur..., ja que ens condueix cap a una altra composició, un tercer sonet que, de ben segur, ens pot ajudar a aprofundir en les qüestions esmentades fins ara, i, en conseqüència, a entendre millor la naturalesa de la resta de poemes estudiats en aquest article. I és que, tal com ens indica el mateix Màrius Torres, En el silenci obscur... parteix en el seu origen d'un poema anterior que el precedeix, un poema del Les Fleurs du mal, de l'obra magna Charles Baudelaire: La Musique (Baudelaire, 1975: 68). En aquesta composició, com passava en el text del poeta lleidatà, Baudelaire descriu els efectes que li produeix la música a través d'una sèrie de símils mariners. De fet, el poeta francès construeix una elaborada analogia entre les emocions que li suggereix aquesta forma artística i la sensació de navegar en un veler desbocat, que avança de forma salvatge a través d'una mar embravida:

\section{LA MUSIQUE}

La musique souvent me prend comme une mer !

Vers ma pâle étoile,

Sous un plafond de brume ou dans un vaste éther,

Je mets à la voile ;

La poitrine en avant et les poumons gonflés

Comme de la toile

J'escalade le dos des flots amoncelés

Que la nuit me voile ;

Je sens vibrer en moi toutes les passions

D'un vaisseau qui souffre ;

Le bon vent, la tempête et ses convulsions

Sur l'immense gouffre

Me bercent. D'autres fois, calme plat, grand miroir

De mon désespoir !

Tot seguit en presentem la traducció catalana (Calsina, 2017: 73):

\section{LA MÚSICA}

La música sovint em pren com una mar!

Vers la blanca estrella,

sota el vast firmament o en un cel emboirat, 
arboro la vela;

amb el pit endavant $i$ els pulmons insuflats igual que una tela

escalo sobre el llom de l'onatge eriçat que la nit em vela;

sento glatir dins meu totes les passions d'un veler en sofrença;

la brisa, la tempesta, i ses convulsions

dins la gorja immensa

em bressen. Altres cops, gran repòs, mirall llis del meu desencís!

A través de la lectura del text, podem comprovar el poder que la música exerceix sobre el subjecte poètic. La música el transporta, l'empeny, el remou com unes aigües desbocades, li produeix uns efectes profunds i poderosos. Ja des de la primera línia, ens diu que el pren com una mar, que el porta a navegar sota d'un èter immens, que totes les passions el dominen, etc., en una mena de viatge oníric a través del poder que exerceix damunt seu la força del ritme i de l'harmonia. Ara bé, després de tota l'energia despresa al llarg del poema, en els darrers versos trobem un detall inaudit, sorprenent, un detall molt important que, de fet, trastoca completament el sentit últim del text. És aleshores, en els darrers versos, quan reconeix que aquesta meravella potser es produeix «souvent», com deia a l'inici, però no sempre, i que «d'autres fois», en canvi, la música esdevé alguna cosa completament distinta, un «grand miroir de mon desespoir», és a dir, un mirall immens de la seva desesperança.

Aquests versos finals són bàsics per comprendre el sentit últim del poema. La música potser és una força que serveix per amplificar els sentiments i les percepcions però, tal com ens indica el text, aquesta expansió de les emocions no és necessàriament bona. En realitat, pot ser tant positiva com, amb la mateixa intensitat, negativa. La música és tan meravellosa com també pot ser igualment horrible i terrorífica. Aquesta és la seva verdadera naturalesa. És, per tant, una visió complexa de la música, caracteritzada per una marcada dualitat. Un concepte, el 
de dualitat, que no en va té una gran importància en l'obra de Baudelaire i que sovint aplica a diverses realitats com són la bellesa, el bé i el mal, o, fins i tot, la mateixa ànima humana ${ }^{1}$.

Però, en veritat, voldríem analitzar amb especial detall l'aspecte tècnic del poema. I és que, sens dubte, es tracta d'un bell exemple, especialment aconseguit i interessant, de la relació que es pot establir en poesia entre la forma dels versos i el seu contingut. La Musique és una composició marcadament rítmica, com no pot ser d'altra manera en un poema que duu aquest títol. D’entrada, si ens fixem en l'estructura mètrica, hem de parar esment en la combinació que s'estableix entre versos alexandrins i pentasíl·labs. Aquesta curiosa combinació crea un efecte sincopat, d'estrany bransoleig, que sens dubte pretén imitar el moviment de la mar i dels vaixells, el gronxament característic que produeixen les onades ${ }^{2}$. Es tracta d'un element retòric molt significatiu.

Però més enllà d'això, cal que ens fixem sobretot en els darrers versos de la composició, tal com comentàvem fa un moment. En aquest punt hi trobem un segon joc retòric que, segurament, encara és més significatiu, més transcendent. Es tracta d'uns versos on Baudelaire utilitza la combinació entre el ritme i la sonoritat per amplificar el missatge autèntic i profund del poema:

Sur l'immense gouffre

Me bercent. D'autres fois, calme plat, grand miroir

De mon désespoir!

Sens dubte, Baudelaire volia atorgar un gran pes a aquest final. De fet, si analitzem rítmicament i auditiva aquests versos ens adonem que estan construïts amb una calculada precisió: podem observar una estructura rítmica constant en el primer fragment $\left(-_{-}{ }^{\wedge}\right)$ que es repeteix tres

$1 \quad$ Vegeu, per exemple, el poema Hymne à la Beauté (Baudelaire, 1975: 10), on aquesta idea resulta ben clara i manifesta. També en són bons exemples L'albatros (Baudelaire, 1975: 9), Élevation (Baudelaire, 1975: 10) o tal vegada Semper eadem i Confesion, on es fa palesa la dualitat en l'esperit de la seva estimada (Baudelaire, 1975: 41, 45, 46). D'altra banda, en la seva prosa assagística Baudelaire teoritzava de manera més directa sobre diverses idees relacionades amb aquest concepte de dualitat. A Le Peintre de la vie moderne, per exemple, es referia a la natura doble de la bellesa, i arribava a afirmar que aquesta no és sinó una conseqüència de la dualitat de l'ànima humana (Baudelaire, 1980: 791). També, una mica més endavant en aquest mateix llibre, Baudelaire parla de la dualitat que s'estableix entre el bé i el mal, i entre naturalesa i civilització (Baudelaire, 1980: 809, 810).

2 Aquesta idea ja la planteja John E. Jackson a les notes de la seva edició (Jackson, 2014: 300). Claude Pichois, de la seva banda, afirma que és l'únic poema de Les Fleurs du mal en què l'alexandrí s'associa a un vers de cinc síl·labes (Baudelaire, 1975: 964). 
vegades, i que és succeïda per una progressió un mica més llarga en el darrer vers, just abans de resoldre en l'accent final $\left(----^{\wedge}\right)$. A més, cada accent rítmic coincideix amb el fonema [a] el qual, a banda de provocar una rima consonant entre els dos darrers versos, també forma una rima interna en el penúltim. Per tal de mostrar aquesta estructura d'una forma més visual, hem elaborat el següent esquema:

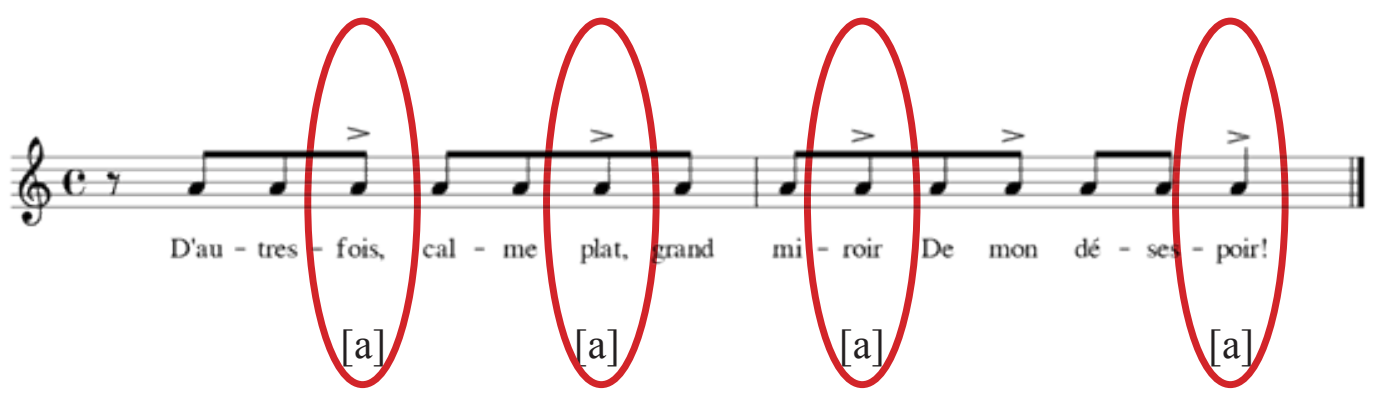

És evident que aquesta combinació d'accents sobre el fonema [a] no pot ser una casualitat. I és que, a través d'aquesta progressió rítmica i fonètica, Baudelaire buscava carregar de significança el versos finals. És a dir, que a través de la forma, el poeta francès volia ressaltar el canvi d'orientació que pren el poema en els darrers versos: la música pot ser un paradís, però també pot ser un infern. Així, vist des d'aquest punt de vista, el poema pren una nova dimensió i significat a través de l'extraordinària relació que planteja entre forma i contingut.

Per tant, després d'haver analitzat aquests tres poemes -Escuchando la música sacra..., En el silenci obscur... i La Musique- podem reprendre el comentari de Trio en do menor de Pere Rovira amb una perspectiva més àmplia i profunda. Resulta palès que en tots els textos, però sobretot els poemes de Torres i Baudelaire, es desenvolupen un sèrie d'elements que, no per casualitat, estan estretament relacionats amb la composició de Rovira: el dolor i el patiment, l'alegria i la joia, el desig d'evasió, la visió matisada i dual de la realitat, la reflexió sobre el fenomen musical, etc. Certament, en tots els casos trobem una percepció de la música que resulta complexa, en cap cas unívoca o simplista. La música no és ni bona ni dolenta, ni positiva ni negativa, sinó que la interpretació del fenomen sembla més pregona, més complicada, potser ambivalent. Es podria afirmar que la idiosincràsia d'aquesta forma d'expressió condueix, sobretot, a amplificar el sentiments humans, a fer-los créixer, a donar-los una transcendència que, en darrer extrem, resulta quasi sobrenatural. Per tot plegat, la naturalesa dels sentiments que indueix tampoc 
no hauria de ser monolítica ni unitària, sinó al contrari, és també una naturalesa dividida, que pot conduir tant al dolor més intens i profund com a una joia extremament exultant.

Es podria pensar, doncs, que els poemes de Torres i Rovira són deutors, en bona mesura, de la composició de Baudelaire; i, en veritat, la importància de l'autor francès per als dos poetes catalans és considerable. Ara bé, és igualment important remarcar les singularitats evidents de cadascun d'aquests dos textos. En el cas d'En el silenci obscur..., l'autor lleidatà s'inclina per incidir particularment en la funció que exerceix la música; aquesta forma artística es converteix, principalment, en una forma d'evasió, en una manera d'embriagar-se i de fugir dels embats d'una existència dolorosa, asfixiant, que colpeix al subjecte poètic d'una manera punyent ${ }^{3}$. Tot i que aquest no és segurament el lloc per estendre's en aspectes biogràfics, no és sobrer apuntar l'evident lligam que presenta aquesta extraordinària composició amb el context personal del mateix poeta.

Pel que fa a Rovira, també hem d'exposar diversos trets particulars que caracteritzen el poema, atès que el text conjuga la tradició amb una sèrie de matisos més personals. Sens dubte, podem afirmar que totes aquestes qüestions, tot aquest llegat literari, es pot percebre de forma clara en el text de Pere Rovira, però en la formulació de les seves conclusions finals sembla lleugerament distinta. Així, si a l'inici ens preguntàvem sobre els sentiments experimentats pel subjecte poètic de Trio en do menor, sobre la naturalesa de la música que defensava, ara podem respondre que, en efecte, són uns sentiments i una naturalesa complexos, però que per damunt de tot, hi domina una sensació d'incertesa. La música amplifica les emocions del protagonista del poema, tant les bones i positives com també les més doloroses. Això porta a una certa perplexitat al personatge que, lluny d'establir unes asseveracions taxatives sobre el procés catàrtic que sofreix, el que fa justament és preguntar-se sobre el propi procés en què es troba immers. A diferència de Torres i Baudelaire no es tracta només d'una evasió, tampoc d'una explicació contundent del fenomen, sinó que, precisament, és una reconeixença dels seus dubtes i incerteses.

3 Val a dir que, de fet, el concepte d'evasió, encara que no aparegui expressat explícitament a La Musique, també és recurrent a l'obra poètica de Charles Baudelaire. Vegeu el poema Enivrez-vous, de Petites poèmes en prose, (Baudelaire, 1975: 337), que és, probablement, l'exemple més paradigmàtic d'aquesta qüestió. 
D’aquí que el poeta utilitzi un recurs peculiar que no és altre que dirigir-se directament a la música, tot plantejant una sèrie de preguntes retòriques que, com és obvi, no tenen resposta. No poden tenir resposta.

De fet, aquest principi d'incertesa és un valor important en el pensament de Pere Rovira, el qual, en els darrers anys, s'ha mostrat cada vegada menys partidari de les postures massa taxatives i concloents pel que fa a tot tipus d'experiències artístiques, i, en especial, quant al fenomen concret de la poesia (Rovira, 2016: 7, 8):

\footnotetext{
En otras épocas de mi vida, en mi juventud, supe cómo tenía que ser la poesía. Sabía cómo eran las circunstancias sociales en que se producía, quién debía protagonizarla, cómo tenía que sonar la voz que la decía y, por lo tanto, con qué música fluirían los versos. Me ocupé tanto en saber todo esto, que mi escritura poética empezó a escasear y hubo un momento en que corrió el riesgo de no existir. [...]
}

Ahora ya soy viejo, y sospecho que la mayor parte de las seguridades tratan de esconder la incertidumbre. Creo que es mejor manifestarla, ponerla en primer plano, pues de la incertidumbre puede quizá extraerse más libertad y más placer que de la obstinada certeza.

Per tant, sembla que Rovira es decanta per incidir en una postura intencionadament més dubitativa, d'acceptació de la desconeixença i les pròpies limitacions. No es tracta tant de donar unes respostes concretes a la qüestió que tracta el poema com de presentar la magnitud de les preguntes, l'amplitud del fenomen que planteja.

I, de fet, el recurs utilitzat per assolir aquest objectiu, les diverses preguntes retòriques formulades a una realitat abstracte, és també una influència de Charles Baudelaire. No en va, en el poema Hymne à la Beauté (Baudelaire, 1975: 10) trobem una situació molt semblant a aquesta, una situació on la veu poètica interpel·la, en aquest cas, a la bellesa -que esdevé, així, personificada-, i li pregunta sobre el seu origen i la seva naturalesa. Endemés, la coneixença d'aquest poema per part de Rovira és indubtable, ja que ell mateix va escriure'n una traducció d'excel·lent factura tècnica (Rovira, 2008: 21):

Viens-tu du ciel profond ou sors-tu de l'abîme,

Ô Beauté? Ton regard, infernal et divin,

Verse confusément le bienfait et le crime, 
Et l'on peut pour cela te comparer au vin.

(vv.1-4)

¿Baixes del cel profund o has sortit de l'abisme,

Bellesa?, el teu esguard, infernal i diví,

al crim i a la bondat confusament inclina,

i per això podem comparar-te amb el vi.

(vv.1-4)

En conclusió, hem d'afirmar que Trio en do menor és un interessant exemple de l'ús de la tradició en la poesia recent de Pere Rovira. L'autor català sap adoptar la riquesa del llegat literari, especialment del corrent simbolista, i construeix un poema nou d'enorme profunditat emotiva i conceptual. Les concomitàncies amb altres poemes i autors diversos és molt significativa, important, matisada i d'una altíssima complexitat. Aquest domini de la tradició simbolista evidencia, doncs, que Rovira segueix una tendència ben marcada, i que, de manera més o menys conscient, s'inscriu en aquesta tradició literària que s'inicia en Baudelaire i que ha tingut en Màrius Torres un dels millors representants en llengua catalana. 


\section{Bibliografia}

Andrade, P. (1995). «El papel de la música en la formación de la nueva poética a finales del siglo XIX», en Revista de Filología Francesa, Volum 7, pp. 31-44. Madrid: Publicaciones de la UCM.

Balakian, A. (1969). El movimiento simbolista. Madrid: Guadarrama.

Ballart, P. i Julià J. (2012). Pere Rovira. Paraula encesa, pp. 391-393. Barcelona: Viena Edicions.

Ballart, P. i Julià, J. (2013). Pere Rovira. Que van a dar en la mar. Antología poética mediterránea, pp. 183-193. Barcelona: Serveis de Publicacions de la UAB.

Baudelaire, Ch. (1975). Euvres complètes. Paris: Gallimard.

Baudelaire, Ch. (1980). Euvres complètes. Paris: Éditions Robert Laffont.

Baudelaire, Ch. (2014). Les Fleurs du Mal. Paris: Librairie Général Française.

Benjamin, W. (2014). Baudelaire. Madrid: Abada Editores.

Calsina, J. (2017). Entre tu i jo, nosaltres. Barcelona: Servei de Publicacions de la UAB.

Chestier, A. (2003). La littérature du silence. Paris: L'Harmattan.

De Azúa, F. (1999). Baudelaire y el artista de la vida moderna. Barcelona: Anagrama.

Gallego, V. (2002). Santa deriva. Madrid: Visor Libros.

Jankélévitch, V. (1983). La musique et l'ineffable. Paris: Le Seuil.

Macià, X. (2008). «L'art de mesurar distàncies. Poesia completa de Pere Rovira», en Reduccions, Volum 91, pp. 99-106.

Mallarmé, S. (1945). «La musique et les lettres», en CEuvres complètes. Paris: Gallimard.

Margarit, J. (2003). «Navegant per un mar interior», en Caràcters, Volum 24, pp. 26-27. 
Michaud, G. (1947). Méssage poétique du Symbolisme. París: Nizet.

Pàmies, J. (1982). «Temes principals en la poesia de Màrius Torres», en Reduccions, Volum 16, pp. 71-90.

Rovira, P. (1981). Distàncies. València: Eliseu Climent.

Rovira, P. (1989). Cartes marcades. Barcelona: Península-Edicions 62.

Rovira, P. (1996). La vida en plural. Barcelona: Columna.

Rovira, P. (2002). La mar de dins. Barcelona: Proa.

Rovira, P. (2008). Vint-i-cinc flors del mal. Lleida: Universitat de Lleida.

Rovira, P. (2009). Les roses de Ronsard. Barcelona: Proa.

Rovira, P. (2011). Contra la mort. Barcelona: Proa.

Rovira, P. (2016). Poética y poesía. Madrid: Fundación Juan March.

Subiràs, M. (1993). «Màrius Torres i la música», en Estudis de llengua i literatura catalanes, Miscel-lània Jordi Carbonell, Volum XXVI, pp. 95-112. Barcelona: Abadia de Montserrat.

Torres, M. (2010). Poesies de Màrius Torres. Lleida: Pagès Editors.

Torres, M. (2011). Les coses tal com són. Barcelona: Acontravent. 